\title{
Aplicação do Target Costing e Engenharia do Valor na Precificação de Curso de Pós-Graduação
}

Paulo Wienhage
Mestrado em Ciências Contábeis pela Fundação Universidade Regional de Blumenau -
FURB
Professor do Instituto Blumenauense de Ensino Superior e da Sociedade Leonardo da
Vinci
Rua São Paulo, 3250. Itoupava Seca. Blumenau/SC
E-mail: pwienhage@hotmail.com

Irani Rocha Mestrado em Ciências Contábeis pela Universidade Regional de Blumenau - FURB Professora da Faculdade Metropolitana de Blumenau Rua São Paulo, 3250. Itoupava Seca. Blumenau/SC

E-mail: iranirch@gmail.com

Jorge Eduardo Scarpin Doutorado em Controladoria e Contabilidade pela Faculdade de Economia e Administração da Universidade de São Paulo - FEA/USP Professor da Universidade Regional de Blumenau - FURB Rua Antônio da Veiga, 140, Sala D 202. Victor Konder. CEP: 89012-900 E-mail: jorgescarpin@furb.br

\section{RESUMO}

Este estudo investiga o impacto da aplicação da Target Costing e da Engenharia do Valor na precificação de um curso de pós-graduação lato sensu. A metodologia nesta pesquisa tem caráter descritivo do tipo levantamento ou survey e o instrumento para coleta de dados foi um questionário. Também foram realizadas entrevistas com a direção e coordenadores da IES, além da análise das planilhas de custos do curso de pós-graduação. Quanto à abordagem, se caracteriza como quantitativa, e os dados foram coletados no mês de novembro de 2009. A população é composta por 298 alunos, sendo 165 respondentes válidos. A pesquisa não busca identificar a metodologia de custeio empregada pela IES, mas sim utilizar a metodologia do Target Costing, aliada a Engenharia do Valor, como instrumento para analisar os custos do curso de pós-graduação e verificar a possibilidade de atingir o preço idealizado pelo público consumidor. Entre os resultados constatou-se que com a redução de alguns custos foi possível adequar o preço do curso de acordo com as necessidades do mercado.

Palavras-chave: Target Costing. Engenharia do Valor. Curso Pós-Graduação. 


\section{Application of Target Costing and Value Engineering in Pricing Postgraduate} Course

\section{ABSTRACT}

This study investigated the impact of applying the Target Costing and Value Engineering in the pricing of a postgraduate course in the broad sense. The methodology in this research is descriptive nature of this survey type and the instrument for data collection was a questionnaire, were also conducted interviews with directors and coordinators of $\mathrm{HEI}$, also analysis of cost spreadsheets course graduate. As the approach is characterized as quantitative, data were collected in November 2009. The populations is composed of 298 students, 165 valid respondents. The survey does not seek to identify the cost methodology employed by the HEI, but to use the methodology of Target Costing, together with Value Engineering as a tool to analyze the costs of post-graduate course and to verify the possibility of achieving the price designed by consuming public. Among the findings revealed that the reduction of some costs could bring the price of the course according to market needs.

Keywords: Target Costing. Value Engineering. Postgraduate Course.

\section{INTRODUÇÃO}

Para a organização se manter inserida no mercado, considera-se necessário que a mesma volte sua atenção para o consumidor, caso isso não aconteça, perdas de fatias do mercado podem ocorrer. Nesse contexto, o grande desafio para as empresas se manterem no mercado competitivo de hoje, é conseguir que todos os custos exigidos para plena satisfação dos clientes sejam cobertos pelos preços dos produtos e serviços. Dessa forma, são grandes as dificuldades para as empresas de manufatura, para as empresas de comercialização de produtos, assim como para as prestadoras de serviços (ROTTA, 2005).

Em outros tempos as organizações calculavam seus custos, definindo uma margem de lucro necessária e assim chegavam ao preço de venda do seu produto ou serviço. Frente à competitividade que as mesmas se encontram, o mercado é quem estabelece o preço de venda, ou seja, existe um preço estabelecido por este com base na percepção de valor dada pelos consumidores, dessa maneira, a empresa sente-se obrigada a adotá-lo como única forma de haver demanda para o produto ou serviço que estiver oferecendo. Considerando que o mercado é quem estipula o preço de venda, a 
empresa necessita ajustar sua estrutura de custos para obter a rentabilidade desejada. Nesse sentido, pode-se citar a metodologia do custeio alvo ou custeio meta como um dos modelos que trabalha com esta visão (BOMFIM, 2006).

Custeio-Alvo ou Target Costing é o processo de avaliação e redução de custos que analisa características, funcionalidades e competitividade dos produtos. Para Sakurai (1997, p. 49) o Target Costing é "um método abrangente de gerenciamento estratégico de custos que envolvem a redução de custos durante todo o ciclo de sua ocorrência". Assim, conforme Pompermayer (2004), o objetivo do custo-alvo é gerenciar o lucro da empresa determinado pela meta de redução de custos com base nos processos de desenvolvimento, produção e distribuição dos produtos. Não somente a contabilidade, mas também o planejamento estratégico da empresa integra-se ao custeio-alvo, pois integra a participação de fornecedores e à análise dos aspectos do mercado.

Já a Engenharia do Valor é um método que permite à empresa inovar, desenvolver novos produtos e melhorar os processos de produção, analisar os custos associados e em seguida tentar melhorar os componentes, através da redução de custos sem redução da qualidade.

Nesse sentido, para as organizações fixarem seus preços, não é algo tão simples assim, é necessário conhecimento referente à situação econômica, a concorrência, as estratégias de marketing e o tipo de mercado em que a empresa está inserida. Dessa maneira, conhecer apenas os custos dos produtos ou serviços não é suficiente para definição do preço. A organização deverá utilizar-se de um sistema de custos que produza informações que atendam a filosofia da empresa (MARTINS, 2003).

Dada a necessidade de investigar o processo de melhora na tomada de decisões empresariais quanto à definição de preços para seus produtos ou serviços, emerge a pergunta que norteia esta pesquisa: Qual o impacto da aplicação do Target Costing e Engenharia do Valor para a precificação de um curso de Pós-Graduação? Para tanto, este estudo tem como objetivo investigar o impacto da aplicação da metodologia Target Costing e Engenharia do Valor na precificação de um curso de Pós-Graduação. 
A escolha do tema justifica-se pela importância e relevância que as instituições de ensino têm para a sociedade, uma vez que estas são em parte responsáveis pelos bons profissionais que a todo ano são inseridos no mercado de trabalho. Dessa maneira, estudar os custos dos serviços corrobora com Allora e Allora (1995), quando destacam a importância do custo para a organização, considerando o custo à própria vida da empresa, ressaltando, assim, que os dirigentes deveriam dedicar sua máxima atenção no momento de precificar os seus produtos ou serviços.

O presente estudo está organizado por uma primeira seção de caráter introdutório, seguindo o referencial teórico, abordando-se os conceitos de Target Costing bem como os estudos anteriores realizados sobre esta temática; na seção 3 tem-se uma breve revisão da literatura que aborda a Engenharia do Valor. Na quarta parte apresenta-se o método e os procedimentos metodológicos; na seção 5 apresentase a análise dos resultados; e por fim a seção 6 tece reflexões e faz recomendações para pesquisas futuras.

\section{TARGET COSTING}

\subsection{Definição de Target Costing}

A prática da utilização do custo é uma ferramenta de grande importância nos dias de hoje devido à grande competitividade que existe entre as empresas, já que a qualidade dos produtos é similar e seus preços são semelhantes. Mediante esta situação, os pesquisadores vêm buscando alternativas para reduzir os custos, esmerando-se por encontrar sistemas de gestão de custos que forneçam informações adequadas a rotina empresarial quanto ao custo dos produtos e processos de manufatura, e, principalmente, que atendam as necessidades dos consumidores quanto à qualidade e preços (PAREDES, 2004).

Segundo Scarpin (2000), o Target Costing, também conhecido por Genka Kikaku, Custeio Alvo ou Custeio Meta, surgiu no Japão em 1965, criado pela empresa Toyota e desenvolvido por empresas japonesas como um instrumento para medir os 
custos em período pós-guerra, quando o país passava por uma série de problemas com escassez de recursos e de pessoal.

Sakurai (1997, p. 52) conceitua o Target Costing como "um processo estratégico de gerenciamento de custos para reduzir os custos totais, nos estágios de planejamento e de desenho do produto". Di Stefano e Alderete (2001) corroboram com o posicionamento de Sakurai e destacam que este método representa um mecanismo para unir todas as áreas funcionais da empresa e se encontra estreitamente vinculado com o planejamento e a tomada de decisão.

Freitas (2004, p. 5) expande o conceito para o Target Costing, pois para este autor essa metodologia representa um

\footnotetext{
Sistema de gestão estratégica de custos e planejamento de lucros centrado principalmente nas fases de pesquisa, desenvolvimento e engenharia do produto, que guiado pelo preço de mercado, tem por finalidade obter o custo máximo aceitável de um produto, de maneira a alcançar uma rentabilidade razoável, satisfazendo clientes, considerando todo o ciclo de vida do produto e envolvendo toda a estrutura organizacional e cadeia de valor da empresa.
}

Conforme a definição apresentada, entende-se que este é um método de gerenciamento de custos voltado para atender as necessidades e ânsias do mercado consumidor.

Essa metodologia amplamente utilizada pelas empresas japonesas, $80 \%$ das indústrias japonesas a utilizam, tem pouca aplicação no Brasil. Pesquisas empíricas verificaram a utilização do Target Costing na prestação de serviços, Hansen (2002) defendeu em sua dissertação de mestrado a Aplicação do Custeio Alvo em cursos de pós-graduação e Camacho (2004) investigou o Custeio Alvo em serviços hospitalares (CAMACHO; ROCHA, 2007).

\subsection{Target Costing e a visão tradicional de formação de preços de venda}

Bomfim (2006, p. 16) destaca que a base do Target Costing é a administração dos custos a partir do conhecimento antecipado de qual deverá ser o preço de venda do produto ou serviço admitido pelo mercado, e da margem de lucro necessária para 
garantir a continuidade da empresa e o alcance das metas estabelecidas pela sua gestão.

Segundo Kotler (1995), a formação do preço de venda do produto ou serviço, pode ocorrer com base nos custos, sendo esta a forma mais tradicional de precificação, porém o autor explica que há outras formas de determinar o preço de venda, estas com base no valor que se baseia na percepção do cliente sobre o valor do produto.

Para Rocha e Martins (1999, p. 83) é neste momento, quando se tem conhecimento do preço de venda que o mercado está disposto a pagar, que a empresa deve obter o custo máximo admissível do produto ou serviço para que, dado o preço de venda vigente no mercado, consiga o mínimo de rentabilidade que se pretende, antes do início da produção. Corroborando com Rocha e Martins (1999), Bomfim (2006) esclarece que ao empregar a metodologia do Target Costing para precificar os produtos, tendo por base o preço de venda, as empresas devem adequar os seus custos, buscando os ajustes necessários para por o produto em produção ou então eliminá-lo.

Scarpin (2000), baseando-se na literatura existente, comparou as diferenças entre a precificação pela abordagem tradicional e pela metodologia determinada pelo Target Costing e chegou aos seguintes resultados, conforme Quadro 1. 


\begin{tabular}{|c|c|}
\hline Custeio Meta & Abordagem tradicional de custos \\
\hline O preço determina o custo. & O custo determina o preço. \\
\hline $\begin{array}{l}\text { Começa com um preço de mercado (ou preço } \\
\text { alvo de venda) e uma margem de lucro } \\
\text { planejada para depois estabelecer um custo } \\
\text { permissível (ou custo alvo). }\end{array}$ & $\begin{array}{l}\text { Estima um custo de produção, depois } \\
\text { acrescenta uma margem de lucro desejada para } \\
\text { então se obter um preço de venda. }\end{array}$ \\
\hline $\begin{array}{l}\text { Planejamento de custos é guiado pelo mercado } \\
\text { competitivo. }\end{array}$ & $\begin{array}{l}\text { As considerações de mercado não são } \\
\text { consideradas no planejamento de custos. }\end{array}$ \\
\hline $\begin{array}{l}\text { Reduções de custos são feitas antes que os } \\
\text { custos cheguem ao seu limite aceitável. }\end{array}$ & $\begin{array}{l}\text { Reduções de custos são feitas depois } \\
\text { que os custos são incorridos além do limite } \\
\text { aceitável. }\end{array}$ \\
\hline $\begin{array}{l}\text { O projeto (de produtos e processos) é a chave } \\
\text { para reduções de custos. }\end{array}$ & $\begin{array}{l}\text { Perdas e ineficiências são o foco da } \\
\text { redução de custos. }\end{array}$ \\
\hline $\begin{array}{l}\text { Reduções de custos são guiadas pelos desejos } \\
\text { e anseios do consumidor. }\end{array}$ & $\begin{array}{l}\text { Redução de custos não são dirigidas aos } \\
\text { clientes. }\end{array}$ \\
\hline $\begin{array}{c}\text { Custos são gerenciados por equipes } \\
\text { multifuncionais (toda a empresa). }\end{array}$ & $\begin{array}{c}\text { Os custos são monitorados apenas pelos } \\
\text { contadores. }\end{array}$ \\
\hline $\begin{array}{c}\text { Fornecedores são envolvidos no conceito e no } \\
\text { projeto. }\end{array}$ & $\begin{array}{l}\text { Os fornecedores são envolvidos apenas } \\
\text { na fase de produção (depois do projeto pronto). }\end{array}$ \\
\hline $\begin{array}{c}\text { Minimiza o custo de propriedade para o } \\
\text { consumidor. }\end{array}$ & $\begin{array}{c}\text { Minimiza apenas o preço pago pelo } \\
\text { consumidor. }\end{array}$ \\
\hline $\begin{array}{l}\text { Envolve toda a cadeia de valor no planejamento } \\
\text { de custos. }\end{array}$ & $\begin{array}{l}\text { Pouco ou nenhum envolvimento da } \\
\text { cadeia de valor no planejamento de Custos. }\end{array}$ \\
\hline
\end{tabular}

Quadro 1: Comparativo entre Target Costing e a Abordagem Tradicional de Formação de Preço de Venda

Fonte: Scarpin (2000).

Conforme evidenciado no Quadro 1, há necessidade de planejamento e união de todos os setores da empresa para que se possa utilizar a metodologia do Target Costing na formação de preço, inclusive de fornecedores, mas, principalmente, conhecer os anseios do consumidor. Scarpin (2000) infere que existem divergências quanto aos métodos relacionados ao Target Costing e a abordagem tradicional. São elas, no que se refere ao relacionamento com o ambiente externo, o Custeio Meta interage com este ambiente para responder às necessidades do mercado e do consumidor, já a abordagem tradicional simplesmente ignora o ambiente externo, medindo internamente suas ineficiências. 


\section{ENGENHARIA DO VALOR}

A Análise do Valor representa uma metodologia que permite desenhar ou redesenhar produtos e serviços com redução de custos, visando à satisfação e necessidades do usuário, é, também, um método que possibilita restaurar a competitividade. A literatura define que os termos Engenharia do Valor (EV) e a Analise do Valor (AV) não são sinônimos, pois a engenharia do Valor é aplicada na fase de projeto, enquanto que a Análise do Valor na fase de desenvolvimento.

De acordo com Miles (1972), a Engenharia do Valor é a busca para ter o custo mais baixo possível e o máximo de criação de valor para o cliente, ou seja, conseguir das funções de um produto, ou serviço, confiabilidade e competitividade do produto sem perder a qualidade.

Sakurai (1997) afirma que a Engenharia do Valor pode ser entendida como um conjunto de métodos que designam a projeção de um novo produto com o mais baixo custo possível e com as funções requisitadas pelos consumidores. Assim, a função é o efeito de um produto ou de um de seus componentes para atender às necessidades do cliente e o valor da relação entre uma função destinada a satisfazer o cliente e os custos dessa função.

Segundo Ansari et al. (1997), esta metodologia é muito utilizada no estágio de projeto do produto para ampliar o valor do cliente e diminuir os custos antes que a produção tenha começado. Basso (1991) justifica que nada mais justo que formar o custo de um produto levando em consideração as funções desempenhadas por ele e determina que o custo na abordagem convencional é formado pela soma da matériaprima mais a mão de obra e as despesas gerais, enquanto que na abordagem da Análise do Valor este é constituído pelas suas funções: básica, secundária e as desnecessárias.

Csillag (1995) esclarece que a metodologia não significa, obrigatoriamente, uma redução de custos. Nesta linha de raciocínio, Pereira filho (1994, p. 22) explica que "os resultados da $A \bigvee / E V$ não só conduzem para a redução de custos, mas também no 
sentido de aperfeiçoar os diversos requisitos definidos para o produto, ou pelo menos se reduzem os custos mantendo-se as especificações do objeto em análise".

\section{METODOLOGIA DA PESQUISA}

No que se refere à metodologia, esta pesquisa se caracteriza como exploratória. Vieira (2002, p. 5) afirma que "a pesquisa exploratória visa proporcionar ao pesquisador uma maior familiaridade com o problema em estudo". Assim, esse estudo classifica-se como exploratório uma vez que busca conhecer as ansiedades dos alunos com relação ao custo do curso. Para realização da pesquisa foi adotada a estratégica de levantamento de dados ou survey que procura "descrever com exatidão algumas características de populações designadas" (TRIPODI; FELLIN; MEYER, 1981, p. 39). Dessa forma pretendeu-se conhecer a opinião dos futuros discentes acerca do que eles esperam do curso em que estão se inserindo.

Tabela 1: Amostra da Pesquisa

\begin{tabular}{|c|c|c|c|c|}
\hline Curso & $\begin{array}{c}\text { Total de } \\
\text { alunos/candidatos }\end{array}$ & Respondentes & $\begin{array}{c}\text { Participação } \\
\%\end{array}$ & $\begin{array}{c}\text { Não tem interesse } \\
\text { no curso }\end{array}$ \\
\hline $\begin{array}{c}\text { Ciências } \\
\text { Contábeis }\end{array}$ & 55 & 40 & 72,73 & 02 \\
\hline Direito & 108 & 52 & 48,15 & 14 \\
\hline Administração & 120 & 81 & 67,50 & 06 \\
\hline Matemática & 15 & 14 & 93,33 & 00 \\
\hline Total & $\mathbf{2 9 8}$ & $\mathbf{1 8 7}$ & $\mathbf{6 2 , 7 5}$ & $\mathbf{2 2}$ \\
\hline
\end{tabular}

Fonte: dados da pesquisa

Conforme Tabela 1, a população é composta por 298 alunos, potenciais candidatos ao curso de Pós-Graduação. Compõem a amostra 187 alunos que responderam o instrumento de avaliação do grau de influência sobre a decisão de fazer o referido curso. Destaca-se que 22 alunos demonstraram não ter interesse no curso, portanto foram considerados como respondentes válidos apenas 165 . Os respondentes são alunos matriculados em uma Universidade localizada na mesma região da Instituição de Ensino Superior (IES) objeto deste estudo. É importante destacar que a IES é uma Faculdade, localizada em Santa Catarina, que oferece, a nível de 
graduação, apenas cursos de Tecnólogos e que os alunos matriculados nestes cursos não representam o público-alvo para o curso de pós-graduação lato sensu objeto desta pesquisa.

Para resguardar e por solicitação da própria IES, não se informa o seu nome neste trabalho. O curso de pós-graduação, no momento desta pesquisa, encontrava-se em fase de planejamento por parte da IES, ou seja, ainda não havia entrado em fase de comercialização.

Cabe mencionar que os respondentes foram escolhidos de forma intencional, por sua acessibilidade e se caracterizarem como público-alvo do curso. Assim, caracterizase como uma amostragem não-probabilística e intencional, que, segundo Marconi e Lakatos (1996), devem ser utilizadas quando se está interessado na opinião de determinados elementos da população, mesmo que não se possa representar o todo.

Como instrumento de coleta de dados, para sentir a percepção dos futuros alunos, utilizou-se o questionário desenvolvido por Bomfim (2006). Também foram realizadas entrevistas com a Direção e Coordenadores da IES, além da análise das planilhas de custos do curso de pós-graduação.

Quanto à abordagem, esta se caracteriza como quantitativa. Conforme Richardson et al. (1999, p. 70), "o método quantitativo, como o próprio nome indica, caracteriza-se pelo emprego da quantificação tanto nas modalidades de coleta de informações, quanto no seu tratamento por meio de técnicas estatísticas, desde as mais simples como as mais complexas". Os dados foram coletados no mês de novembro de 2009 e tabulados em planilha do Microsoft Excel.

É importante destacar que esta pesquisa não busca identificar a metodologia de custeio empregada pela IES, mas sim utilizar a metodologia do Target Costing, aliada a Engenharia do Valor, como instrumento para analisar os custos do curso de pósgraduação e verificar a possibilidade de atingir o preço idealizado pelo público consumidor. 


\section{ANÁLISE DOS RESULTADOS}

Inicialmente foram tabulados os questionários aplicados junto aos alunos dos cursos de graduação em Ciências Contábeis, Direito, Administração e Matemática, pois o curso de Pós-Graduação investigado tem como público alvo estes futuros profissionais. Na Tabela 2 destacam-se os possíveis valores para o curso e a opção dos respondentes. Destaca-se que $25,45 \%$ dos respondentes têm interesse em pagar pelo curso de pós-graduação, desde que este tenha suas parcelas com valores entre $R \$ 400,00$ a $R \$ 500,00$.

Tabela 2: Preço máximo a pagar mensalmente por um curso de Pós-Graduação

\begin{tabular}{|c|c|c|}
\hline Alternativa & Respondentes & Participação \% \\
\hline Até $R \$ 300,00$ & 33 & 20,00 \\
\hline $\begin{array}{c}\text { De } R \$ 301,00 \text { até } R \$ \\
400,00\end{array}$ & 32 & 19,39 \\
\hline $\begin{array}{c}\text { De } R \$ 401,00 \text { até } R \$ \\
500,00\end{array}$ & 42 & 25,45 \\
\hline $\begin{array}{c}\text { De } R \$ 501,00 \text { até } R \$ \\
600,00\end{array}$ & 27 & 16,36 \\
\hline $\begin{array}{c}\text { De } R \$ 601,00 \text { até } R \$ \\
700,00\end{array}$ & 18 & 10,91 \\
\hline $\begin{array}{c}\text { De } R \$ 701,00 \text { até } R \$ \\
800,00\end{array}$ & 4 & 2,42 \\
\hline $\begin{array}{c}\text { De } R \$ 801,00 \text { até } R \$ \\
900,00\end{array}$ & 3 & 1,82 \\
\hline Acima de $R \$ 901,00$ & 6 & 3,64 \\
\hline Total & $\mathbf{1 6 5}$ & $\mathbf{1 0 0 , 0 0}$ \\
\hline
\end{tabular}

Fonte: dados da pesquisa.

Após tabulados os dados foi possível obter o valor da parcela, $R \$ 462,00$, que os alunos estariam dispostos a pagar pelo curso de Pós-Graduação, conforme Tabela 3. 
Tabela 3: Definição do valor da parcela do curso de Pós-Graduação na visão dos alunos

\begin{tabular}{|c|c|c|c|c|c|c|c|c|}
\hline $\begin{array}{c}\text { Valor Médio das Mensalidades } \\
\mathrm{R} \$\end{array}$ & 250,00 & 350,00 & 450,00 & 550,00 & 650,00 & 750,00 & 850,00 & 950,00 \\
\hline $\begin{array}{c}\text { Porcentagem de alunos } \\
\text { optantes }\end{array}$ & 20,00 & 19,39 & 25,45 & 16,36 & 10,91 & 2,42 & 1,82 & 3,64 \\
\hline Valor Médio do Curso R $\$$ & 50,00 & 67,88 & 114,55 & 90,00 & 70,91 & 18,18 & 15,45 & 34,55 \\
\hline Valor da Parcela do Curso R $\$$ & \multicolumn{7}{|c|}{$\mathbf{4 6 1 , 5 2 = 4 6 2 , 0 0}$} \\
\hline
\end{tabular}

Fonte: dados da pesquisa.

Conforme Bomfim (2006, p.130), "a técnica aplicada foi a definição de um valor médio dentro das faixas de preços mencionadas, em um intervalo de $\mathrm{R} \$ 100,00$ ". Desta forma, na opção entre $R \$ 301,00$ e $R \$ 400,00$, foi definido o valor médio de $R \$ 350,00$, sobre o valor determinado foi aplicado o percentual de respondentes obtido. O mesmo procedimento se deu para todas as faixas e após somou-se o valor, obtendo-se assim 0 valor de $\mathrm{R} \$ 462,00$, que os alunos estariam dispostos a pagar pelo curso.

O questionário também possibilitou conhecer o número de parcelas que os alunos estariam dispostos a pagar pelo curso. A Tabela 4 apresenta o resultado da pesquisa, sendo que 54 respondentes apresentam interesse em pagar o curso em doze parcelas, já 39 respondentes manifestaram interesse em pagar o curso em dezoito parcelas.

Tabela 4: Número máximo de parcelas a pagar pelo curso

\begin{tabular}{|c|c|c|}
\hline Alternativa & Respondentes & Participação \% \\
\hline A vista & 6 & 3,64 \\
\hline Até três parcelas & 6 & 3,64 \\
\hline Até seis parcelas & 8 & 4,85 \\
\hline Até dez parcelas & 11 & 6,67 \\
\hline Até doze parcelas & 54 & 32,73 \\
\hline Até quinze parcelas & 8 & 4,85 \\
\hline Até dezoito parcelas & 39 & 23,64 \\
\hline Acima de dezoito parcelas & 33 & 20,00 \\
\hline Total & $\mathbf{1 6 5}$ & $\mathbf{1 0 0 , 0 0}$ \\
\hline
\end{tabular}

Fonte: dados da pesquisa.

Para se obter o número ideal de parcelas do curso, na visão do mercado consumidor, foram consideradas as respostas dos alunos, seguindo a mesma linha de 
raciocínio aplicada à faixa de valores. Conforme os dados apurados na Tabela 5, o número ideal e parcelas para o curso de pós-graduação é de 15 parcelas.

Tabela 5: Definição do valor da parcela do curso de Pós-Graduação na visão dos alunos

\begin{tabular}{|c|c|c|c|c|c|c|c|c|}
\hline Respondentes & 6 & 6 & 8 & 11 & 54 & 8 & 39 & 33 \\
\hline $\begin{array}{c}\text { Porcentagem de alunos } \\
\text { optantes }\end{array}$ & 3,64 & 3,64 & 4,85 & 6,67 & 32,73 & 4,85 & 23,64 & 20 \\
\hline Número Médio de Mensalidades & 1 & 3 & 6 & 10 & 12 & 15 & 18 & 21 \\
\hline Número de Parcelas do Curso & \multicolumn{7}{|c|}{15} \\
\hline
\end{tabular}

Fonte: dados da pesquisa.

Dando sequência à análise, verificaram-se as características comerciais para o curso de pós-graduação oferecido pela Instituição de Ensino Superior, que a princípio estava dividido em 18 parcelas de $R \$ 542,00$, totalizando $R \$ 9.756,00$ por aluno, conforme Tabela 6. Na composição do preço de venda estão incluídos custos relativos aos docentes, material didático, outros custos diretos e uma parcela para cobrir os custos indiretos da IES. Vale destacar que nesta composição não há previsão de lucro e tampouco impostos, devido à forma jurídica da Instituição de Ensino Superior. A IES é uma entidade sem fins lucrativos, não é tributada por nenhum imposto sobre as suas receitas nas esferas federal, estadual e municipal. De acordo com Basso (1991, p. 1), "neste caso o Preço deve ser igual ao Custo".

Tabela 6: comparação do custo Preço de venda por aluno com o preço de venda estimado por aluno

\begin{tabular}{|c|c|c|c|}
\hline Alternativa & Parcelas & $\begin{array}{c}\text { Valor } \\
\text { Parcela }\end{array}$ & $\begin{array}{c}\text { Total Curso } \\
\text { (R\$) }\end{array}$ \\
\hline Instituição & 18 & 542,00 & $9.756,00$ \\
\hline Interesse dos Alunos & 15 & 462,00 & $6.930,00$ \\
\hline
\end{tabular}

Fonte: dados da pesquisa.

A direção da IES destacou que a planilha de custos elaborada requer que o curso tenha no mínimo 25 alunos, embora turmas com menos alunos possam ser realizadas, após uma breve análise dos custos, nas quais deverá ser levada em consideração uma redução dos custos indiretos na composição do valor da parcela. $O$ 
curso ora analisado será oferecido apenas pela IES, não havendo concorrência no mercado.

Tabela 7: Planilha de custo do curso de pós-graduação para 25 alunos

\begin{tabular}{|c|rr|rr|}
\hline Recursos utilizados & Valor Unitário & \multicolumn{2}{|c|}{ Custo em R\$ } \\
\hline Gastos com professores & & $\mathrm{R} \$$ & $124.025,90$ \\
\hline Coordenação do curso & & & $\mathrm{R} \$$ & $20.700,00$ \\
\hline Apostila & $\mathrm{R} \$$ & 115,00 & $\mathrm{R} \$$ & $2.875,00$ \\
\hline Folheto Síntese do Curso & $\mathrm{R} \$$ & 2,50 & $\mathrm{R} \$$ & 62,50 \\
\hline Caneta Personalizada & $\mathrm{R} \$$ & 22,00 & $\mathrm{R} \$$ & 550,00 \\
\hline Lapiseira Personalizada & $\mathrm{R} \$$ & 22,00 & $\mathrm{R} \$$ & 550,00 \\
\hline Pasta personalizada & $\mathrm{R} \$$ & 65,00 & $\mathrm{R} \$$ & $1.625,00$ \\
\hline Guia para Elaboração de Trabalhos & $\mathrm{R} \$$ & 2,50 & $\mathrm{R} \$$ & 62,50 \\
\hline Manual do Aluno & $\mathrm{R} \$$ & 2,50 & $\mathrm{R} \$$ & 62,50 \\
\hline Palestras & & & $\mathrm{R} \$$ & $3.000,00$ \\
\hline Cerimônia de abertura & & & $\mathrm{R} \$$ & $2.600,00$ \\
\hline Cerimônia de encerramento & & & $\mathrm{R} \$$ & $2.800,00$ \\
\hline Eventos especiais extra-aulas & & & $\mathrm{R} \$$ & 800,00 \\
\hline Brindes & & $\mathrm{R} \$$ & 800,00 \\
\hline Certificado & $\mathrm{R} \$$ & 50,00 & $\mathrm{R} \$$ & $1.250,00$ \\
\hline Coffee Break & $\mathrm{R} \$$ & 7,80 & $\mathrm{R} \$$ & $20.475,00$ \\
\hline Rateio Custo Indireto & $\mathrm{R} \$$ & 45,00 & $\mathrm{R} \$$ & $18.900,00$ \\
\hline Inadimplência Evasão & & & $\mathrm{R} \$$ & $35.453,10$ \\
\hline Apoio comercial & & & $\mathrm{R} \$$ & $7.309,92$ \\
\hline Valor total por Turma & & & $\mathbf{R} \$$ & $\mathbf{2 4 3 . 9 0 1 , 4 2}$ \\
\hline Valor da parcela (18 parcelas/25 & & & $\mathbf{R} \$$ & $\mathbf{5 4 2 , 0 0}$ \\
\hline alunos) & & & &
\end{tabular}

Fonte: dados da pesquisa.

A Tabela 7 apresenta os componentes do custo de uma turma do curso de pósgraduação. Os gastos com professores representam os valores das horas trabalhadas, mais o repouso semanal remunerado e os encargos sociais. Também foram adicionadas as despesas com transportes, refeições e hospedagem.

Além disso, são considerados os valores para material didático utilizado no curso, outros custos de apoio pedagógico, previsão de inadimplência e evasão, verba para divulgação do curso e uma parcela para cobrir os custos indiretos da IES. Segundo a direção da IES, o cálculo para se fazer o rateio dos custos indiretos é proporcional a capacidade instalada, ou seja, os custos totais indiretos são divididos pela capacidade total instalada, apurando-se o custo indireto de uma hora, como o 
curso de pós-graduação apresenta uma carga horária de 420 horas e o custo indireto de uma hora apurado na IES é de $R \$ 45,00$, o curso de pós-graduação deverá contribuir com $\mathrm{R} \$ 18.900,00$ para as despesas indiretas.

Tabela 8: custo estimado para turmas com 25 alunos

\begin{tabular}{|c|c|}
\hline Descrição & Total Curso (R\$) \\
\hline Preço de venda bruto & $243.901,42$ \\
\hline (-) Parcela dos custos indiretos & $18.900,00$ \\
\hline (-) Inadimplência Evasão & $35.453,10$ \\
\hline (-) Apoio Comercial & $7.309,92$ \\
\hline = Custo Estimado IES & $\mathbf{1 8 2 . 2 3 8 , 4 0}$ \\
\hline
\end{tabular}

Fonte: dados da pesquisa.

A Tabela 8 apresenta o preço de venda total para uma turma do curso de pósgraduação de 25 alunos. Para obter o custo estimado foram excluídos os valores correspondentes a parcela que o custo deve cobrir dos custos indiretos, a inadimplência e evasão e a verba destinada ao apoio comercial.

Tabela 9: custo máximo admissível para turmas com 25 alunos, na visão dos alunos

\begin{tabular}{|c|c|}
\hline Descrição & Total Curso (R\$) \\
\hline Preço de venda bruto & $173.250,00$ \\
\hline (-) Parcela dos custos indiretos & $18.900,00$ \\
\hline (-) Inadimplência Evasão & $25.987,50$ \\
\hline (-) Apoio Comercial & $7.309,92$ \\
\hline = Custo Máximo Admissível alunos & $\mathbf{1 2 1 . 0 5 2 , 5 8}$ \\
\hline
\end{tabular}

Fonte: dados da pesquisa.

Da mesma forma que foram excluídos os valores dos custos e despesas para se obter o custo máximo admissível para a IES, custo estimado, utilizou-se o mesmo parâmetro para se definir o custo máximo admissível na concepção dos alunos, conforme Tabela 9. 
Tabela 10: Custo IES - custo máximo admissível para turmas com 25 alunos, na visão dos alunos

\begin{tabular}{|c|c|}
\hline Descrição & Total Curso (R\$) \\
\hline Custo Máximo Admissível IES & $182.238,40$ \\
\hline Custo Máximo Admissível alunos & $121.052,58$ \\
\hline $\begin{array}{c}\text { Custo alvo (custo IES - custo máximo admissível } \\
\text { alunos) }\end{array}$ & $\mathbf{6 1 . 1 8 5 , 8 2}$ \\
\hline Custo alvo em percentual do estimado & $33,57 \%$ \\
\hline
\end{tabular}

Fonte: dados da pesquisa.

Conforme determinado pela metodologia do Target Costing, é necessário conhecer o valor do custo alvo. Bertucci (2008) esclarece que o custo alvo é a diferença entre o custo estimado pela empresa e o custo máximo admissível pelo mercado. Bomfim (2006, p. 42) destaca que o custo alvo representa o gap, "o qual se deve eliminar". A Tabela 10 apresenta o custo determinado pela IES e o custo máximo admissível, na visão dos alunos. No caso o custo alvo é de $\mathrm{R} \$ 61.185,82$, ou seja, uma redução de $33,57 \%$ nos custos, que deverá ser eliminado a fim de atender a demanda de mercado.

Tabela 11: Grau de importância dos atributos do curso

\begin{tabular}{|c|c|c|c|c|c|}
\hline \multirow[t]{2}{*}{ COMPONENTES/ATRIBUTOS } & \multicolumn{5}{|c|}{ Importância dos Atributos } \\
\hline & 4 & 3 & 2 & 1 & Total \\
\hline Coffee-break & $31 \%$ & $38 \%$ & $20 \%$ & $11 \%$ & $100 \%$ \\
\hline Titulação do docente (doutor) & $55 \%$ & $40 \%$ & $3 \%$ & $2 \%$ & $100 \%$ \\
\hline Titulação do docente (mestre) & $55 \%$ & $41 \%$ & $3 \%$ & $2 \%$ & $100 \%$ \\
\hline Titulação do docente (especialista) & $51 \%$ & $36 \%$ & $7 \%$ & $5 \%$ & $100 \%$ \\
\hline Acompanhamento do coordenador & $65 \%$ & $32 \%$ & $1 \%$ & $2 \%$ & $100 \%$ \\
\hline Palestras & $41 \%$ & $45 \%$ & $13 \%$ & $1 \%$ & $100 \%$ \\
\hline Material didático - Apostilas & $52 \%$ & $36 \%$ & $8 \%$ & $4 \%$ & $100 \%$ \\
\hline Pastas Personalizadas & $13 \%$ & $18 \%$ & $35 \%$ & $33 \%$ & $100 \%$ \\
\hline Caneta Personalizada & $8 \%$ & $11 \%$ & $33 \%$ & $48 \%$ & $100 \%$ \\
\hline Lapiseira Personalizada & $8 \%$ & $13 \%$ & $30 \%$ & $48 \%$ & $100 \%$ \\
\hline Guia para Elaboração de Trabalhos Acadêmicos & $40 \%$ & $47 \%$ & $10 \%$ & $3 \%$ & $100 \%$ \\
\hline Manual do Aluno (informações: direitos/deveres do aluno) & $21 \%$ & $45 \%$ & $23 \%$ & $11 \%$ & $100 \%$ \\
\hline Folheto Síntese do Curso (apresentação do curso) & $35 \%$ & $38 \%$ & $22 \%$ & $5 \%$ & $100 \%$ \\
\hline Eventos especiais extra-aulas & $26 \%$ & $48 \%$ & $19 \%$ & $7 \%$ & $100 \%$ \\
\hline Cerimônia de abertura & $10 \%$ & $32 \%$ & $34 \%$ & $24 \%$ & $100 \%$ \\
\hline Cerimônia de encerramento & $17 \%$ & $37 \%$ & $28 \%$ & $18 \%$ & $100 \%$ \\
\hline Brindes & $10 \%$ & $24 \%$ & $36 \%$ & $30 \%$ & $100 \%$ \\
\hline Certificado & $83 \%$ & $12 \%$ & $2 \%$ & $2 \%$ & $100 \%$ \\
\hline
\end{tabular}

Fonte: dados da pesquisa. 
Para eliminar o custo alvo utiliza-se a técnica de Engenharia do Valor. Seguindo esta metodologia na Tabela 11 destaca-se o grau de importância dos atributos do curso na visão dos alunos. No instrumento de coleta de dados os respondentes deveriam escolher qual dos atributos/funções do curso de pós-graduação consideravam mais importantes, nas asserções foi utilizada a escala Likert de 4 pontos, que se baseia em uma escala que inicia em "4 - muito importante", "3 - importante", "2 - pouco importante" e "1 - dispensável".

O grau de importância dos atributos do curso na visão dos alunos, conforme demonstrado na Tabela 12, representa em termos proporcionais o quanto cada recurso necessário para a realização do curso é importante dentro do conjunto de recursos disponíveis. O resultado é obtido através da divisão do percentual de cada item do produto por 100 e multiplicado pela escala de importância do atributo, exemplificando: Grau de Importância do Atributo, Tabela 11, Coffee-Break: $(0,31 \times 4)+(0,38 \times 3)+$ $(0,20 \times 2)+(0,11 \times 1)=2,89$, o que significa que o atributo é "importante" para os alunos, pois está perto de 3. Ainda na Tabela 12 também é apresentado o Grau de Importância Relativa dos Atributos, que é obtido através do cálculo que considera a participação do atributo no todo, exemplificando: Grau de Importância Relativa do Atributo Coffee-Break (em \%) $=(2,89 / 51,73) \times 100=5,59 \%$. Neste caso o atributo mais importante na visão dos alunos, potenciais clientes, é o certificado com $7,23 \%$, seguido do acompanhamento do coordenador com $6,79 \%$ e o de menor importância são as canetas, lapiseiras e pastas personalizadas.

A coluna seguinte da Tabela 12 evidencia os recursos necessários para que cada atributo seja atendido, sendo eles MD: material direto, PD: pessoal direto, MI: material indireto e PI: pessoal indireto, sendo que podem ser necessários mais de um recurso para um único atributo. 
Aplicação do Target Costing e Engenharia do Valor na Precificação de Curso de Pós-Graduação

Paulo Wienhage, Irani Rocha, Jorge Eduardo Scarpin

Tabela 12: Grau de Importância Relativa (IR) dos recursos necessários para atender aos atributos do curso

\begin{tabular}{|c|c|c|c|c|c|}
\hline Itens/Atributos & Grau de importância & $\begin{array}{l}\text { Grau de } \\
\text { IR dos } \\
\text { atributos }\end{array}$ & $\begin{array}{l}\text { Recursos } \\
\text { Utilizados }\end{array}$ & $\begin{array}{l}\text { Contribuição } \\
\text { em relação } \\
\text { ao atributo }\end{array}$ & $\begin{array}{c}\text { Importância } \\
\text { Relativa }\end{array}$ \\
\hline Coffee-break & 2,89 & $5,59 \%$ & MD & $100 \%$ & $5,59 \%$ \\
\hline $\begin{array}{l}\text { Titulação do docente } \\
\text { (doutor) }\end{array}$ & 3,48 & $6,73 \%$ & PD & $100 \%$ & $6,73 \%$ \\
\hline $\begin{array}{l}\text { Titulação do docente } \\
\text { (mestre) }\end{array}$ & 3,51 & $6,79 \%$ & PD & $100 \%$ & $6,79 \%$ \\
\hline $\begin{array}{l}\text { Titulação do docente } \\
\text { (especialista) }\end{array}$ & 3,31 & $6,40 \%$ & PD & $100 \%$ & $6,40 \%$ \\
\hline $\begin{array}{l}\text { Acompanhamento do } \\
\text { coordenador }\end{array}$ & 3,60 & $6,96 \%$ & PD & $100 \%$ & $6,96 \%$ \\
\hline Palestras & 3,26 & $6,30 \%$ & $\mathrm{PI}$ & $100 \%$ & $6,30 \%$ \\
\hline $\begin{array}{c}\text { Material didático - } \\
\text { Apostilas }\end{array}$ & 3,36 & $6,50 \%$ & MD & $100 \%$ & $6,50 \%$ \\
\hline $\begin{array}{c}\text { Pastas } \\
\text { Personalizadas }\end{array}$ & 2,09 & $4,04 \%$ & MD & $100 \%$ & $4,04 \%$ \\
\hline $\begin{array}{c}\text { Caneta } \\
\text { Personalizada }\end{array}$ & 1,79 & $3,46 \%$ & MD & $100 \%$ & $3,46 \%$ \\
\hline $\begin{array}{c}\text { Lapiseira } \\
\text { Personalizada }\end{array}$ & 1,79 & $3,46 \%$ & MD & $100 \%$ & $3,46 \%$ \\
\hline $\begin{array}{c}\text { Guia para } \\
\text { Elaboração de } \\
\text { Trabalhos }\end{array}$ & 3,24 & $6,26 \%$ & MD & $100 \%$ & $6,26 \%$ \\
\hline Manual do Aluno & 2,76 & $5,34 \%$ & MD & $100 \%$ & $5,34 \%$ \\
\hline $\begin{array}{l}\text { Folheto Síntese do } \\
\text { Curso }\end{array}$ & 3,03 & $5,86 \%$ & MD & $100 \%$ & $5,86 \%$ \\
\hline $\begin{array}{c}\text { Eventos especiais } \\
\text { extra-aulas }\end{array}$ & 2,93 & $5,66 \%$ & $\begin{array}{l}\mathrm{MI} \\
\mathrm{Pl}\end{array}$ & $\begin{array}{l}50 \% \\
50 \%\end{array}$ & $\begin{array}{l}2,83 \% \\
2,83 \%\end{array}$ \\
\hline $\begin{array}{l}\text { Cerimônia de } \\
\text { abertura }\end{array}$ & 2,28 & $4,41 \%$ & $\begin{array}{l}\mathrm{MI} \\
\mathrm{Pl}\end{array}$ & $\begin{array}{l}50 \% \\
50 \%\end{array}$ & $\begin{array}{l}2,205 \% \\
2,205 \% \\
\end{array}$ \\
\hline $\begin{array}{l}\text { Cerimônia de } \\
\text { encerramento }\end{array}$ & 2,53 & $4,89 \%$ & $\begin{array}{l}\mathrm{MI} \\
\mathrm{PI}\end{array}$ & $\begin{array}{l}50 \% \\
50 \%\end{array}$ & $\begin{array}{l}2,445 \% \\
2,445 \%\end{array}$ \\
\hline Brindes & 2,14 & $4,14 \%$ & $\mathrm{Ml}$ & $100 \%$ & $4,14 \%$ \\
\hline Certificado & 3,74 & $7,23 \%$ & MD & $100 \%$ & $7,23 \%$ \\
\hline & 51,73 & $100,00 \%$ & & & $100,00 \%$ \\
\hline
\end{tabular}

Fonte: dados da pesquisa.

Os dados constantes da Tabela 13 foram obtidos das tabelas 7 e 12. Da tabela 7 os dados relativos aos custos, excluindo-se os valores relativos ao pagamento da parcela do custo indireto da IES, inadimplência e evasão e apoio comercial, da Tabela 12 o Grau de Importância Relativa aos Atributos.

O Custo Relativo (CR) é obtido pela divisão do custo de cada componente pelo custo total, o Índice de Valor (IV) é determinado pela divisão da Importância Relativa 
(IR) pelo Custo Relativo (CR). Segundo Camacho (2004, p. 105) o ideal é que o IV fique próximo de 1 , pois este

representa a relação entre a importância relativa de um recuso e seu custo relativo. Índices de Valor (IV) acima de 1 significam que o Custo Relativo do recurso é menor que o seu grau de importância relativa. Por outro lado, Índices de Valor baixo de 1 significam que o custo Relativo do recurso é maior que o seu grau de importância relativa.

Tabela 13: Custo Relativo (CR) e Índice de Valor (IV) dos recursos

\begin{tabular}{|c|c|c|c|c|c|c|}
\hline Recursos utilizados & $\begin{array}{c}\text { Custo } \\
\text { Atual em } \\
\text { R\$ }\end{array}$ & CR & IR & IV & $\begin{array}{c}\text { Custo } \\
\text { Máx. } \\
\text { Admissível } \\
\text { R\$ }\end{array}$ & $\begin{array}{l}\text { Variação } \\
\text { R\$ }\end{array}$ \\
\hline Gastos com professores & $124.025,90$ & $68,06 \%$ & $19,90 \%$ & $0,29 \%$ & $24.089,46$ & $99.936,44$ \\
\hline Coordenação do curso & $20.700,00$ & $11,36 \%$ & $6,96 \%$ & $0,61 \%$ & $8.425,26$ & $12.274,74$ \\
\hline Apostila & $2.875,00$ & $1,58 \%$ & $6,50 \%$ & $4,11 \%$ & $7.868,42$ & $(4.993,42)$ \\
\hline Folheto Síntese do Curso & 62,50 & $0,03 \%$ & $5,86 \%$ & $195,33 \%$ & $7.093,68$ & $(7.031,18)$ \\
\hline Caneta Personalizada & 550,00 & $0,30 \%$ & $3,46 \%$ & $11,53 \%$ & $4.188,42$ & $(3.638,42)$ \\
\hline Lapiseira Personalizada & 550,00 & $0,30 \%$ & $3,46 \%$ & $11,53 \%$ & $4.188,42$ & $(3.638,42)$ \\
\hline Pasta personalizada & $1.625,00$ & $0,89 \%$ & $4,04 \%$ & $4,54 \%$ & $4.890,52$ & $(3.265,52)$ \\
\hline $\begin{array}{c}\text { Guia para Elaboração de } \\
\text { Trab. }\end{array}$ & 62,50 & $0,03 \%$ & $6,26 \%$ & $208,67 \%$ & $7.577,89$ & $(7.515,39)$ \\
\hline Manual do Aluno & 62,50 & $0,03 \%$ & $5,34 \%$ & $178,00 \%$ & $6.464,21$ & $(6.401,71)$ \\
\hline Palestras & $3.000,00$ & $1,65 \%$ & $6,30 \%$ & $3,82 \%$ & $7.626,31$ & $(4.626,31)$ \\
\hline Cerimônia de abertura & $2.600,00$ & $1,43 \%$ & $4,41 \%$ & $3,08 \%$ & $5.338,42$ & $(2.738,42)$ \\
\hline Cerimônia de encerramento & $2.800,00$ & $1,54 \%$ & $4,89 \%$ & $3,18 \%$ & $5.919,47$ & $(3.119,47)$ \\
\hline $\begin{array}{l}\text { Eventos especiais extra- } \\
\text { aulas }\end{array}$ & 800,00 & $0,44 \%$ & $5,66 \%$ & $12,86 \%$ & $6.851,58$ & $(6.051,58)$ \\
\hline Brindes & 800,00 & $0,44 \%$ & $4,14 \%$ & $9,41 \%$ & $5.011,58$ & $(4.211,58)$ \\
\hline Certificado & $1.250,00$ & $0,69 \%$ & $7,23 \%$ & $10,48 \%$ & $8.752,10$ & $(7.502,10)$ \\
\hline Coffee Break & $20.475,00$ & $11,24 \%$ & $5,59 \%$ & $0,50 \%$ & $6.766,84$ & $13.708,16$ \\
\hline & $182.238,40$ & $100,00 \%$ & $100,00 \%$ & & $121.052,58$ & $61.185,82$ \\
\hline
\end{tabular}

Fonte: dados da pesquisa.

A Engenharia do Valor se baseia em dois aspectos fundamentais o valor e a função. Basso (1991, p. 10) destaca que "valor é o menor custo atribuído a um produto ou serviço, que deverá possuir a qualidade necessária para atingir a função desejada", já a "função é uma característica do produto que serve a um propósito útil e atende a uma necessidade real do consumidor". 
De acordo com Biazebete, Borinelli e Camacho (2008, p. 12), os Índices de Valor inferiores a 1 "representam que os custos relativos são maiores que a importância relativa atribuída pelos consumidores". Neste estudo três indicadores apresentam IV menor que 1: gastos com professores, coordenação do curso e Coffee Break.

Finalizado os trabalhos de identificação dos componentes do curso que apresentam um baixo índice de valor e que serão passiveis de análise, o próximo passo é buscar alternativas para eliminar o custo alvo de $\mathrm{R} \$ 61.185,82$, conforme Tabela 10.

$\mathrm{Na}$ Tabela 13, a IR determinada pelo mercado foi utilizada como base para distribuir entre os componentes do curso os Valores Máximos Admissíveis que deveriam ser atribuídos a cada um deles. Por exemplo, para se obter o valor máximo a pagar aos professores aplicou-se o percentual de 19,90\% (o percentual de 19,90 foi obtido da soma dos percentuais relativos aos professores da Tabela 12) sobre o valor do custo máximo admissível determinado pelo mercado, de $R \$ 121.052,58$, obtendo-se desta forma $R \$ 24.089,46$, e assim sucessivamente para todos os recursos.

$\mathrm{Na}$ visão dos alunos, público-alvo, alguns dos atributos do curso não têm importância relativa alta, tais como a pasta, a caneta e a lapiseira personalizada, os brindes e os cerimoniais de abertura e encerramento do curso. Estes componentes, entre outros listados na Tabela 13, ao se fazer a redistribuição dos custos deveriam receber uma parcela maior de valor, porém não há necessidade de maiores gastos, ou aumentar a qualidade destes componentes que já atendem aos padrões de qualidade da IES. Desta forma, os componentes que requerem uma análise mais criteriosa são os valores relativos aos professores, coordenação do curso e Coffee Break.

Analisando a planilha de custo e formação do preço, Tabela 7, juntamente com a Direção da IES foi possível determinar a redução de alguns custos: em relação à coordenação as informações obtidas determinaram que para cada curso de pósgraduação fosse contratado um coordenador específico, porem na estrutura da IES há um coordenador geral para os cursos de pós-graduação. Analisando a estrutura da IES, foi possível determinar que a coordenação do curso pudesse ser feita pelo coordenador geral dos cursos de pós-graduação sem perda da qualidade, eliminando-se assim o valor de $\mathrm{R} \$ 20.700,00$ da planilha de custos. 
É importante destacar que o coordenador geral dos cursos tem seu salário e encargos classificados como custo indireto, de acordo com a metodologia de custeio empregada pela IES, e uma parte deste custo já está computado na planilha sob a rubrica de Rateio do Custo Indireto.

O segundo ponto de análise foram os valores a pagar para os professores. Conforme apurado na Tabela 13, o valor atribuído a este componente deveria ser de apenas $R \$ 24.089,46$, porém sabe-se que em virtude as considerações do mercado este valor torna-se inviável.

Inicialmente, a IES planejou que todos os professores do curso deveriam ser de renomadas instituições de ensino, na sua maioria oriundos do estado de São Paulo. Com isso os custos se tornam elevados, seja pelo valor hora a pagar por estes profissionais e pelas despesas com deslocamento e hospedagem dos mesmos. Para tomar alguma medida que pudesse adequar os custos a realidade de mercado, foi necessário analisar as disciplinas oferecidas no curso e buscar na região professores que estivessem aptos a assumir estas disciplinas e que, consequentemente, implicassem em gastos menores.

É importante destacar que estas análises ocorreram juntamente com a Direção e com o coordenador dos cursos de pós-graduação, que opinou e concordou com alguns aspectos da proposta e discordou de outros, sendo possível ao fim dos trabalhos chegar a um consenso, o que resultou na redução dos gastos com professores em $R \$$ 29.985,82, identificado na Tabela 13.

$\mathrm{Na}$ sequência foram analisados os gastos com Coffee Break. Inicialmente a planilha de custos contemplava $\mathrm{R} \$ 7,80$ por aluno, por encontro. Como o curso deve ter 105 encontros e a previsão é de 25 alunos, o custo total com este item totalizava $R \$$ $20.475,00$. O IV do item acusa 0,67 , identificando que o custo é relativamente alto e não tão importante para os alunos. Desta forma buscou-se uma alternativa para continuar oferecendo o benefício para os alunos, porém, com custo menor. Novamente, em conjunto com a administração da IES foi possível identificar no mercado um fornecedor cujo custo atinge $R \$ 4,00$ por aluno e que atenda a expectativa de ofertar um produto com qualidade, embora em menor quantidade/variedade. A redução de custos com 
Coffee Break atingiu o valor de $\mathrm{R} \$ 9.975,00$, conforme identificado na Tabela 14 , representando uma redução neste item de $R \$ 10.500,00$.

Tabela 14: Custo Máximo Admissível após a transferência de custos entre os recursos

\begin{tabular}{|c|c|c|c|}
\hline Recursos utilizados & $\begin{array}{c}\text { Custo Atual } \\
\text { em R\$ }\end{array}$ & $\begin{array}{c}\text { Custo Máx. } \\
\text { Admissível. R\$ }\end{array}$ & $\begin{array}{c}\text { Variação } \\
\text { R\$ }\end{array}$ \\
\hline Gastos com professores & $124.025,90$ & $94.040,08$ & $29.985,82$ \\
\hline Coordenação do curso & $20.700,00$ & - & $20.700,00$ \\
\hline Apostila & $2.875,00$ & $2.875,00$ & - \\
\hline Folheto Síntese do Curso & 62,50 & 62,50 & - \\
\hline Caneta Personalizada & 550,00 & 550,00 & - \\
\hline Lapiseira Personalizada & 550,00 & 550,00 & - \\
\hline Pasta personalizada & $1.625,00$ & $1.625,00$ & - \\
\hline Guia para Elaboração de & 62,50 & 62,50 & - \\
\hline Trab. & 62,50 & 62,50 & - \\
\hline Manual do Aluno & $3.000,00$ & $3.000,00$ & - \\
\hline Palestras & $2.600,00$ & $2.600,00$ & - \\
\hline Cerimônia de abertura & $2.800,00$ & $2.800,00$ & - \\
\hline Cerimônia de encerramento & 800,00 & 800,00 & - \\
\hline Eventos especiais extra-aulas & 800,00 & 800,00 & - \\
\hline Brindes & $1.250,00$ & $1.250,00$ & - \\
\hline Certificado & $20.475,00$ & $9.975,00$ & $10.500,00$ \\
\hline Coffee Break & $\mathbf{1 8 2 . 2 3 8 , 4 0}$ & $\mathbf{1 2 1 . 0 5 2 , 5 8}$ & $\mathbf{6 1 . 1 8 5 , 8 2}$ \\
\hline
\end{tabular}

Fonte: dados da pesquisa.

A IES em sua planilha de custos e formação do preço de venda contempla valores que deverão ser embutidos na planilha e que a resguardem da evasão e inadimplência, assim como possibilite a divulgação do curso. Estes valores estão contemplados na Tabela 15, que somados ao valor do Custo Máximo Admissível formam o total do curso de pós-graduação, que dividido entre o número de alunos apresenta o valor total por aluno, assim como o valor da parcela do curso de pósgraduação. 
Aplicação do Target Costing e Engenharia do Valor na Precificação de Curso de Pós-Graduação

Paulo Wienhage, Irani Rocha, Jorge Eduardo Scarpin

Tabela 15: Valor da parcela por aluno após aplicação da Engenharia do Valor

\begin{tabular}{|c|c|}
\hline Descrição & Total Curso (R\$) \\
\hline Custo Máximo Admissível & $\mathbf{1 2 1 . 0 5 2 , 5 8}$ \\
\hline (+) Parcela dos custos indiretos & $18.900,00$ \\
\hline (+) Inadimplência Evasão & $25.987,50$ \\
\hline (+) Apoio Comercial & $7.309,92$ \\
= Total do Curso & $\mathbf{1 7 3 . 2 5 0 , 0 0}$ \\
\hline Quantidade Alunos & 25 \\
\hline $\begin{array}{c}\text { (=) Valor por Aluno (total do Curso/Quantidade de } \\
\text { Alunos }\end{array}$ & $\mathbf{6 . 9 3 0 , 0 0}$ \\
\hline Quantidade de Parcelas & 15 \\
\hline (=) Valor da Parcela & $\mathbf{4 6 2 , 0 0}$ \\
\hline
\end{tabular}

Fonte: dados da pesquisa.

Após a aplicação da Engenharia do Valor foi possível atingir o Custo Máximo Admissível, atendendo desta forma a expectativa do mercado consumidor em pagar o curso de pós-graduação em 15 parcelas de $R \$ 462,00$.

\section{CONSIDERAÇÕES FINAIS}

Corroborando com os estudos anteriores de Hansen (2002) e Bomfim (2006), voltados para a aplicação da metodologia Target Costing na prestação de serviços educacionais, esta pesquisa teve por objetivo investigar o impacto da aplicação da metodologia Target Costing e da Engenharia do Valor na precificação de um curso de Pós-Graduação Lato Sensu.

A Instituição de Ensino Superior analisada tem em seu portfólio vários cursos de pós-graduação, porém apenas um foi objeto de investigação neste estudo. O curso planejado pela IES inicialmente estava dividido em 18 parcelas de $R \$ 542,00$, totalizando $\mathrm{R} \$ 9.756,00$ por aluno. Porém o mercado estava disposto a pagar apenas 15 parcelas de $R \$ 462,00$, consequentemente o custo alvo a ser eliminado era de $R \$$ $61.185,82$, ou seja, uma redução de $33,57 \%$ nos custos, que deveria ser suprimido sem, no entanto, reduzir a qualidade. Utilizando a metodologia Target Costing e a Engenharia do Valor foi possível identificar os atributos mais valorizados pelo público alvo e analisar o custo relativo de cada um. 
Ao aplicar a Engenharia do Valor foi necessário fazer a transferência de custos entre os atributos do curso, alguns componentes poderiam ter uma verba maior de recursos, porém, segundo a Direção da IES, estes já atendiam os padrões de qualidade da Instituição e não requerem um incremento. O ponto mais importante foi buscar uma solução para o atributo professores, pois na visão dos alunos este apresentava uma importância atribuída relativamente menor que seu custo, mas neste aspecto é praticamente impossível reduzir valores, pois é necessário se adequar aos valores pagos pelo mercado, entretanto, foi possível obter uma redução deste custo buscando profissionais da região. Outros atributos que apresentaram custo relativo alto e índice de valor baixo foram coordenação do curso e coffee break.

Com a redução destes gastos foi possível adequar o preço do curso de acordo com as necessidades do mercado, confirmando que a aplicação da metodologia do Target Costing aliada a Engenharia do Valor são ferramentas adequadas a gestão de custos nas organizações.

Este trabalho tem por limitação a aplicação da metodologia proposta em apenas um curso de pós-graduação. A partir das limitações deste trabalho, podem-se sugerir novas pesquisas que possam aumentar o conhecimento da metodologia do Target Costing no Brasil, tais como a definição do método ideal de custeio pelas instituições de ensino aliado ao uso do Custeio Alvo e da Engenharia do Valor.

\section{REFERÊNCIAS}

ALLORA, F.; ALLORA, V. (1995). UP': unidade de medida de produção para custos e controles gerenciais das fabricações. Blumenau: Fundação Universidade Regional de Blumenau.

ANSARI, S. et al. (1997). Target Costing: the next frontier in strategic cost management. New York: McGraw-Hill.

BASSO, J. L. (1991). Engenharia e análise do valor - EAV: mais as abordagens da administração, contabilidade e gerenciamento de valor: um guia prático para aplicação. São Paulo, IMAM, 194 p. 
BERTUCCI, C. E. (2008). Custeio alvo na indústria brasileira de autopeças. São Paulo, SP. (Dissertação de Mestrado). Faculdade de Economia, Administração e Contabilidade da Universidade de São Paulo, USP, 216 p.

BEZERRA, F. A. (2000). Gestão Estratégica de Custos: um estudo de caso sobre a aplicabilidade do método de custeio ABC em bancos. São Paulo, SP. (Dissertação de Mestrado). Faculdade de Economia, Administração e Contabilidade da Universidade de São Paulo, USP, 186 p.

BIAZEBETE, C. M.; BORINELLI, M. L.; CAMACHO, R. R. (2008). Análise da aplicação do Custeio Alvo e do Custeio Pleno em indústria de confecções: um estudo de caso. In: Congresso Brasileiro de Custos, 15., Curitiba. Anais... Curitiba: CBC, 2008. CD-ROM.

BOMFIM, G. M. (2006). Gerenciamento de resultados em cursos de pós-graduação Lato Sensu através da metodologia do Custeio Alvo. São Paulo, SP. (Dissertação de Mestrado). Faculdade de Economia, Administração e Contabilidade da Universidade de São Paulo, USP, 135 p.

CAMACHO, R. R. (2004). Custeio-alvo em serviços hospitalares: um estudo sob o enfoque da gestão estratégica de custos. São Paulo, SP. (Dissertação de Mestrado). Faculdade de Economia, Administração e Contabilidade da Universidade de São Paulo - USP, $166 \mathrm{p}$.

CSILLAG, J. M. (1995). Análise do valor. (4 ed.). São Paulo: Atlas.

DI STEFANO, V. ALDERETE, V. (2001). El costeo objetivo: sus defectos de aplicación algunas propuestas de mejora y superación. In VII Congresso Del Instituto Internacional de Costos, Del 4 a 6 julio, 2001. León, España. Universidad de León.

FREITAS, T. A. P. A. (2004). Muito prazer! Target Costing...In Congresso USP De Controladoria e Contabilidade, (4 ed.). São Paulo. Anais... FEA/USP, CD-ROM.

HANSEN, J. E. (2002). Aplicação do custeio alvo em cursos de pós-graduação lato sensu: um estudo sob o enfoque da gestão estratégica de custos. São Paulo, SP. (Dissertação de Mestrado). Faculdade de Economia, Administração e Contabilidade da Universidade São Paulo, USP, 211 p.

HANSEN, J. E.; ROCHA, W. (2004). Custeio Alvo: princípios e requisitos. In: XI Congresso Brasileiro de Custos. Porto Seguro. XI Congresso Brasileiro de Custos.

HENDRIKSEN, E. S.; VAN BREDA, M.I F. (1999). Teoria da Contabilidade. São Paulo: Atlas.

KOTLER, P. (1995). Princípios de marketing. Rio de Janeiro: Prentice Hall do Brasil. (7 ed.). 
MARCONI, M. A.; LAKATOS, E. M. (1996). Técnicas de Pesquisa: planejamento e execução de pesquisas, amostragens e técnicas de pesquisas, elaboração, análise e interpretação dos dados. (3 ed.). São Paulo: Atlas.

MARTINS, E. (2003). Contabilidade de Custos. São Paulo, Atlas.

MILES, L.D. (1972). Techniques of value analysis and engineering. (2 ed.). Edition, New York: McGraw-Hill Book Company.

PAREDES, O. M. (2004). Análisis y gestión estratégia de costos: una estratégia para lograr la competitividad. Vision Gerencial, 3: 16-23.

PEREIRA FILHO, R. R. (1994). Análise do valor: processo de melhoria contínua. São Paulo: Nobel.

POMPERMAYER, C. B. (2004). A influência de fatores organizacionais nos aspectos práticos dos sistemas de gestão de custos. Florianópolis, SC. (Tese de Doutoramento). Programa de Pós-Graduação em Engenharia de Produção. Universidade Federal de Santa Catarina, UFSC.

RICHARDSON, R. J. et al. (1999). Pesquisa social: métodos e técnicas. São Paulo: Atlas.

ROCHA, W.; MARTINS, E. A. (1999). Custeio alvo (target costing). Revista Brasileira de Custos, São Leopoldo, 1, (1): 83-94.

ROTTA, V. C. (2005). A utilização do custeio alvo em empresas prestadoras de serviços de advocacia em processos de concorrência pública. In: Congresso Internacional de Custos. 15. Florianópolis. Anais... Florianópolis: CBC, CD-ROM.

SAKURAI, M. (1997). Gerenciamento integrado de custos. São Paulo: Atlas.

SCARPIN, J. E. (2000). Target Costing e sua utilização como mecanismo de formação de preço de venda para novos produtos. Londrina, PR. (Dissertação de Mestrado). Programa de Pós-Graduação em Contabilidade e Controladoria, Universidade Norte do Paraná, UNIPAR, 173 p.

TRIPODI, T.; FELLIN, P.; MEYER, H.J. (1981). Análise da pesquisa social: diretrizes para o uso de pesquisa em serviço social e ciências sociais. (2 ed.). Rio de Janeiro: Francisco Alves.

VIEIRA, V. A. (2002). As tipologias, variações e características da pesquisa de marketing. Revista FAE, Curitiba, 5 (1): 61-70. 
Aplicação do Target Costing e Engenharia do Valor na Precificação de Curso de Pós-Graduação

Paulo Wienhage, Irani Rocha, Jorge Eduardo Scarpin

Data de Submissão: 12/08/2010

Data de Aceite: 09/01/2012 